\title{
Os Contratados: Uma Forma de Escravidão Disfarçada
}

\section{Paulo Roberto S. Moreira}

O interesse na apresentação do presente trabalho deve-se ao fato de ser parcialmente desconsiderada, pela historiografia regional, a resistência de amplos setores das classes trabalhadoras ainda presos aos laços compulsórios da escravidão, mesmo durante a década de 1880. Referimonos aos contratados (libertos sob cláusula de prestação de serviços).

Normalmente, dá-se como data definitiva da abolição da escravatura, na província, o ano de 1884 , quando ocorreu a "benemérita" campanha emancipatória, levando conseqüentemente a desconsideração das formas de escravidão disfarçada, usadas abundantemente na província (ingênuos e contratados, principalmente).

No presente trabalho, procuraremos abordar alguns aspectos desta questão, concentrando a atenção na capital da província, município sobre o qual possuímos maior número de dados.

Um dos pressupostos básicos do presente trabalho é a falta relativa de mão-de-obra, que ocorria no Rio Grande do Sul, na segunda metade do século XIX. Assim, concordamos com a autora abaixo quando diz:

"[...] confirma-se a caracterização de um mercado de relativa escassez na oferta de mão-de-obra, situação agravada pelo fato de que a debilidade da acumulação da classe dominante local - estancieiros e charqueadores, responsáveis por uma economia subsidiária à economia central exportadora - não permitira a importação em massa de força-de-trabalho livre por ocasião da 'crise de braços' que marcou o fim da escravidão [...]. Os imigrantes 
que chegavam não vinham para suprir as necessidades de força-trabalho do complexo da pecuária tradicional, mas sim para trabalharem para si, como minifundiários." (Pesavento, 1989:28.)

Portanto, se admitirmos a falta relativa de mão-de-obra existente na província, não temos como aceitar a falta de interesses na manutenção do controle sobre o trabalhador escravo (realizada principalmente na forma de contratos de serviços) e uma abolição realizada sem grandes preocupaçōes.

Os números que se tem normalmente para o plantel de escravos são, muitas vezes, errôneos. Tal como acontece com os ingênuos, os contratados (ou os libertáveis, como diz Kátia de Queirós Mattoso), também não constam das estatísticas.

Assim, graças a uma curta e bem sucedida campanha abolicionista, o Rio Grande do Sul teria passado de 60.000 escravos, em 1884, para somente 22.709, em 1885 .

Quando aceitamos quase que integralmente a imagem que é divulgada pela imprensa, no momento em que os acontecimentos se dão (ainda mais na falta de uma imprensa "alternativa"), devemos ter consciência de que alguma coisa está errada. Com uma observação mais detalhada dos dados concretos divulgados pelos jornais, que faziam questão de divulgar as "libertações espontâneos" ocorrida diariamente, podemos ter uma visão diferente.

Segundo os resultados obtidos pelo projeto "Abolicionismo e Trabalho livre no Rio Grande do Sul (1850-1888)", coordenado pela professora Helga L. Piccolo, percebemos que a grande maioria dos escravos, "libertados" em 1884 e nos anos seguintes, continuaram sob 0 controle de seus senhores, através do sistema de contratos de serviço.

Através de levantamento feito nos jornais disponíveis no Museu de Comunicação Social, conseguimos os seguintes significativos dados:

1884: em um total de 352 libertações apuradas, 96 foram "sem qualquer condição ou ônus" (27,3\%), 250 "com contrato de prestação de serviços" (71\%) e 5 "nada constavam";

- a média de prestação de serviços foi de 5,7 anos, sendo que a maioria dos casos (113) referia-se a 7 anos. 
1885: para um total de 301 casos apurados: sem condição alguma: 59 (19,61\%); com condição de prestação de serviços: $(76,77 \%)$; a título oneroso: $10(3,3 \%)$; nada consta: $1(0,33 \%)$;

- a média de prestação de serviços foi de 6 anos, sendo que a maioria (129 casos) constava com 7 anos.

Parece confirmar-se a opinião do autor abaixo sobre os "plantadores escravistas sediados nas regiões onde a produção declinava":

"No ápice da luta de classes, esses plantadores chegaram, sob pressão do movimento antiescravista, a admitir a emancipação, desde que ela assumisse uma dentre duas formas: emancipação condicional, isto é, com cláusula de serviço ( = conservação da escravidão 'disfarçada') ou emancipação com indenização do proprietário (o que equivalia ao reconhecimento da legitimidade da propriedade escrava)." (Saes, 1985:206.)

Da mesma forma que os ingênuos, os contratados mantém seu "valor-trabalho" e, mais do que nos mesmos, o seu "valor-mercadoria". O sistema de contratos foi mais uma forma de protelar a libertação do trabalhador escravo. Sua força de trabalho continuou pertencendo ao seu "contratador" que dela se utilizava em seu próprio serviço ou cedia a outros, como os exemplos abaixo:

"QUEM: quiser comprar 4 anos e 8 meses de serviço de uma contratada apta para todo o serviço por 300 e 500 mil réis, dirija-se em carta fechada à rua Duque de Caxias n. 155, com as iniciais O.P. de E. indicando sua morada para ser procurado." (Jornal Mercantil, $\mathrm{n}^{2} 3$, ano XIV, 5 de janeiro de 1887.)

"Vende-se os serviços de 5 anos de uma escrava muito hábil, para o serviço de uma casa de família, sabendo cosinhar, lavar e engomar perfeitamente; quem pretender dirija-se à casa de Antonio Domingues \& Comp. rua Silva Tavares em frente à doca, n. 2." (Jornal do Comércio, ano XVIII, $\mathrm{n}^{2} 203,29$ de agosto de 1882.)

Valiosas propriedades, eram também caçados e procurados, como escravos, os contratados que fugiam às suas "obrigações": 
"DESDE: setembro do ano passado, que desapareceu a contratada de nome Jeronyma, de cor preta e estatura regular. Foi escrava do Dr. Manoel José de Campos e depois de Antonio de Ávila Campos. Quem dela der notícias à rua do Arvoredo n. 125, será gratificado se o exigir." (Jornal $O$ Conservador, $\mathrm{n}^{\circ} 102$, ano VIII, 7 de maio de 1886.)

"A crioula Domingas, obrigada à prestação de serviços por 7 anos ao Dr. Campos, ausentou-se da cada onde estava alugada desde 25 de dezembro do ano passado. Protesta-se contra quem a tiver acoutada, e remunera a quem der notícias certas do lugar onde oculta-se, na rua Caxias n. 3 , no Menino Deus." ( $O$ Conservador, $\mathrm{n}^{2} 13$, ano IX, 18 de janeiro de 1887.)

DESAPARECEU: o preto contratado Timotheo, de Antonio Martins Damião, quem dele der notícias ou o levar ao Sr. Dr. Chefe de Polícia, será gratificado." (Jornal Mercantil, $\mathrm{n}^{\circ}$ 126, ano XIV, 10 de junho de 1887.)

Da mesma forma, os serviços dos contratados eram deixados, como qualquer propriedade, através dos testamentos. Tal é o caso do testamento de Felicidade Maria de Oliveira Prates, que:

"declarou deixar os serviços por 10 anos do escravo Lucas a seu afilhado Lucas, filho de André Machado Moraes Sarmento, findo este tempo será liberto; deixa para sua afilhada Leonor, filha de sua sobrinha Maria Caetana [...] os serviços por 20 anos da parda Joaquina, findo este praso será liberta [...] declarou deixar os serviços por 8 anos dos escravos Silvano, Quintino, João e Fernando a sua sobrinha Maria Caetana [...]". (Mesa de Rendas/ Fazenda, Porto Alegre, maço 1, 1878, AHRGS.)

Mesmo no início de 1888, ainda encontramos senhores de escravos "concedendo" liberdades, mediante contratos de serviços por três anos; é o caso de três cartas de liberdade de São Martinho: do escravo Benedito (de Maria Alves de Oliveira, de 8 de janeiro de 1888), José (de Santos Sobrinho, de 8 de janeiro de 1888) e do escravo Pedro (de Tristão José de 
Vargas, de 20 de fevereiro de 1888) (Fazenda; Diretoria Geral da Fazenda; Provincial, São Martinho, 1888, maço 3 Sala 3, AHRGS).

Ainda buscando referências, nos resultados do projeto já citado, dirigido pela professora Helga Piccolo, encontramos, com cláusula de prestação de serviço, cerca de $47 \%$ das libertaçōes apuradas em 1886 e 43\%, em 1887. (Com uma média de 4 anos de serviço.)

Quanto ao tratamento dado aos contratados, também não diferia daquele verificado junto aos escravos. É o que demonstra o caso da preta Isidora, ex-escrava de Angelica Benedita da Silva, que, em Rio Pardo, foi castigada por sua ex-senhora e pelo filho da mesma pois, em vez de capinar, "estava dando comida à sua filha pequena" (Delegacia de Polícia de Rio Pardo, maço 21, AHRGS, abril de 1888).

Na mesma cidade, o pardo André, contratado de Sebastião Adolfo da Fontoura Charão, foi agredido pelo filho de seu ex-senhor sob a suspeita de ter ido conversar com os trabalhadores da estrada de ferro e com isso ter se atrasado em seus serviços (Delegacia de Polícia de Rio Pardo, maço 21, AHRGS 17 de junho de 1886).

Em novembro de 1887, o mulato Firmino (de 21 anos) fugiu de seu ex-senhor devido aos maus tratos sofridos, sendo que, na última vez, "tendo seu ex-senhor lhe dado algumas chicotadas, botou-lhe no pescoço um taquaraçu, com uma braça mais ou menos de comprimento, com cordas atadas às pernas e com ele andou trabalhando alguns dias nảo lembrando quantos, a qual depois lhe foi tirada" (Delegacia de Polícia de Rio Pardo, maço 21, AHRGS, novembro de 1887).

Idênticos casos podemos encontrar, em Porto Alegre, como o relatado pelo Chefe de Polícia ao Presidente da Província, em 16 de fevereiro de 1887:

"No dia 21 de dezembro último o delegado de polícia desta capital procedeu, por minha ordem o corpo de delito na pessoa do pardo Antonio, ex-escravo de Manoel Jacinto Lopes, e por este liberto com ônus de prestação de serviço, o qual foi me apresentado pelo cidadão Francioni e outras pessoas, que dizião o ter tomado com a argola e corrente que ainda tinha presa ao tornozelo, do poder de Roque Pinheiro, empregado d'aquele Lopes, que diligenciava conduzi-lo para a casa deste de onde havia o mesmo pardo se evadido, partindo a corrente que tinha a outra extremidade segura a uma 
das portas da cozinha. O paciente que apresentava pelo corpo sinais de sevícias antigas e de recente data, declarou que havia 3 meses que assim o tinham preso e que ali, por diversas vezes fora castigado com vergalho pelo antedito Roque, com ciência de seu ex-senhor. Não obstante terem sido consideradas leves as ofensas ordenei que sem demora se abrisse rigoroso inquérito, mas as testemunhas que depuserão limitaram-se a declarar que haviam visto o pardo Antonio na rua com a corrente presa ao tornozelo resistindo a Roque que a força queria leva-lo para casa de Lopes, não o conseguindo pela intervenção de diversas pessoas que se opuseram e o trouxeram a esta secretaria e que quanto ao fato de ter estado ele preso em casa de seu ex-senhor e de ser castigado com vergalho nada sabiam." (Códice de Polícia, n 107, AHRGS, 16 de fevereiro de 1887.)

Entretanto, o processo continuou sob a pressão do Chefe de Polícia. Foram ouvidas as testemunhas apresentadas pelo ex-escravo que confirmaram suas declarações. Além disso, "procedendo-se a exame na mesma casa, encontrou-se com efeito no portal de uma janela da cozinha vestígio de ter sido ali cravado o grampo de ferro, que terminava a extremidade da corrente".

O "valor-mercadoria" dos contratados também pode ser verificado no tratamento dado às contratadas alugadas como amas de leite. É o que denuncia o artigo da Federação, transcrito abaixo:

"Não só escravos remetidos de outros municípios próximos à capital, como até mesmo libertas por contratos de serviço são alugadas como amas e seus filhos entregues a entes miseráveis e sem coração, que tem por ofício receber as infelizes criancinhas e matá-las à força de alimentos grosseiros ou à fome por uma ínfima remuneração pecuniária." ( $A$ Ordem, de Jaguarão, $\mathrm{n}^{\circ} 1320$, ano XII, $1^{\circledR}$ de abril de 1886.)

Comentando o artigo acima, que trata das negras alugadas como amas de leite, A Ordem (6rgão republicano) diz:

"O fato é realmente revoltante e bem revela os sentimentos desumanos de seus autores. Entretanto, não é só em Porto Alegre onde se cometem esses infanticídios 
lentos. Aqui em Jaguarâo, e cremos que em toda a província, se vão praticando o mesmo, não sendo raro espancar-se a escrava, até as contratadas, por se negarem, por amor de seus filhos, a se alugar para tal fim." (Id. acima.)

Devemos salientar que o aluguel de amas de leite era um negócio extremamente lucrativo, ainda mais quando não levavam junto alguma "cria" que disputasse o leite com a criança para a qual fora alugada. Muitos dos filhos de escravas (e provavelmente contratadas) foram entregues como expostos na Santa Casa de Misericórdia. Em 1877, o solicitador Bonone alugava duas amas de leite, sendo uma com cria, cujo aluguel era de $28 \$ 000$ rs. mensais e, a outra, sem cria, alugada por $40 \$ 000$ rs. mensais. (Jornal Rio Grandense, $\mathrm{n}^{2} 140$, ano XII, 23 de junho de 1877.)

Pressionado pela contestação anti-escravista, mas ao mesmo tempo procurando ao máximo adiar a definitiva libertação até que outras formas de controle e compulsão ao trabalho fossem criadas, e defendendo os proprietários escravistas dos capitais empatados no plantel de escravos, Gaspar Silveira Martins anunciava em 1882:

"[...] o direito de propriedade do senhor sobre o escravo se é legal, näo é legítimo [...]. Por maior que seja o valor de um escravo ele estará pago em 8 anos de serviço. Basta que se decrete que no dia $1^{\circ}$ de janeiro de 1890 não haja mais escravos no Brasil." (Jornal do Comércio, $\mathrm{n}^{2} 28$, ano XVIII, 3 de fevereiro de 1882.)

Pressionados, os senhores de escravos faziam de tudo para disfarçar sua propriedade. A libertação com prestação de serviços preenchia completamente tal requisito:

"Os contratos falseiam os registros oficiais da escravatura. O contratado não é matriculado, mas continua subordinado ao senhor, lembrando como antes o crime abominável da posse do homem sobre homem.

Além disso o contrato que de fato nảo assegura a liberdade imediata do escravisado, isenta o outro contratande do imposto existente na legislação imoral, que por esta forma sanciona a mais aviltante expoliação até hoje conhecida." (A Federação, n² 219, ano IV, 28 de setembro de 1887.) 
Agarrados tenazmente aos seus trabalhadores compulsórios, os charqueadores de Pelotas tomaram atitudes radicais no sentido de capturarem refugiados na Serra dos Tapes. "Partidas" de capitães do mato invadiram a serra com a instrução de "matar a tiros os que tentarem escapar e de atar e açoitar os que forem agarrados", sendo que:

"[...] os pretos assim agarrados pertencem na sua quasi totalidade ao número dos contratados, qualidade que ao menos devia torna-los isentos da pena de açoites [...] alguns d'eles são livres por lei, visto que são maiores de 60 anos." ( $A$ Federação, n² 255, n² IV, 11 de novembro de 1887.)

Entretanto, se a intenção, dos senhores, era adiar a abolição, desejando evitar uma possível desorganização da produção com a saída repentina dos trabalhadores, a dos escravos, era radicalmente contrária. Ao que parece, a resistência dos contratados não demorou muito para acontecer após a "farsa" de 1884.

São inúmeras nos jornais do final da década de 1880 as referências às fugas, prisões por desordem e vagabundagem $\mathrm{e}$ roubo dos contratados. Em 1886, um contratado foi reconhecido por seu "proprietário", servindo no Corpo Policial de Porto Alegre. Através de ofício, Manoel Jacinto Fogaça, residente em Cima da Serra, desejava provar que:

"1e - que o pardo de nome Anacleto, é de propriedade do suplicante e que fugiu de sua compania vindo residir nesta capital.

$2^{2}$ - que o referido Anacleto se acha nesta ocasiảo com praça no Corpo Policial sob o nome suposto de Manoel da Silva.

$3^{\circ}$ - que este indivíduo Manoel da Silva, soldado do Corpo Policial, é o mesmo Anacleto, de propriedade do suplicante" (Requerimentos/Justiça, 1886, maço 237, AHRGS).

Os republicanos, neste período defendendo a abolição imediata, descrevem a situação dos contratados: 
"Os que com honestas intenções libertaram os seus escravos com condição de serviço queixam-se da repugnância que eles mostram em continuar no trabalho e em permanecer na mesma casa. Acusam-nos de ingratidão e injustiça. Eles não são ingratos, são escravos, e não é na condição servil que se cultiva a virtude." (Artigo da Federação de 30 de setembro, publicado pela $A$ Ordem, jornal de Jaguarão em 14 de outubro de 1887.)

Os republicanos, no mesmo artigo acima, preocupados mais com a "desorganização econômica" do que com a "desordem moral", clamam pelo fim da escravidão, pois percebem que "enquanto o trabalho for escravo não se pode regulamentá-lo".

Através das partes diárias dos relatórios prestados pelo Chefe de Polícia ao Presidente da Província, verificamos que na Capital os contratados resistiam às prestações de serviço. Durante o ano de 1886, inúmeros foram os contratados presos, conforme listamos abaixo:

\begin{tabular}{|c|c|c|c|c|}
\hline Nomes & Contratador & Data & Causa & Autoridade \\
\hline (1) - Francisco & - não consta & $15-03-1886$ & (A) & $\mathrm{N} / \mathrm{C}$ \\
\hline (2) - Clemente & - nāo consta & $18-03-1886$ & (B) & $\mathrm{J} / \mathrm{O}$ \\
\hline (3) - Luiz & - Antonio Lopes & $20-03-1886$ & (A) & $\mathrm{N} / \mathrm{C}$ \\
\hline (4) - Avelio & - não consta & $27-03-1886$ & A & $\mathrm{N} / \mathrm{C}$ \\
\hline (5) - Matheus & - Manoel Ribeiro & $27-03-1886$ & (B) & $\mathrm{J} / \mathrm{O}$ \\
\hline (6) - Simão & - não consta & $07-04-1886$ & $\mathrm{n} / \mathrm{c}$ & DP \\
\hline (7) - Zeferino & - não consta & $08-04-1886$ & $\mathrm{n} / \mathrm{c}$ & Sub $/ 1^{\circ}$ \\
\hline (8) - Matheus & - não consta & $28-04-1886$ & (B) & $\mathrm{J} / \mathrm{O}$ \\
\hline (9) - Honorato & - não consta & $21-05-1886$ & (B) & $\mathrm{J} / \mathrm{O}$ \\
\hline (10) - Marcelino & - não consta & $27-05-1886$ & (B) & $\mathrm{J} / \mathrm{O}$ \\
\hline (11) - Liberata & - Camila Antonia da Silva & $31-05-1886$ & (B) & $\mathrm{J} / \mathrm{O}$ \\
\hline (12) - Ambrósio & - năo consta & $22-06-1886$ & $\mathrm{n} / \mathrm{c}$ & $\mathrm{CP}$ \\
\hline (13) - Mariano & - não consta & $22-06-1886$ & $\mathrm{n} / \mathrm{c}$ & $\mathrm{CP}$ \\
\hline (14) - Liberata & - não consta & $30-06-1886$ & $\mathrm{n} / \mathrm{c}$ & $\mathrm{J} / \mathrm{O}$ \\
\hline (15) - Cesario & - D. Antonia M. Silva & $17-07-1886$ & (B) & $\mathrm{J} / \mathrm{O}$ \\
\hline (16) - Helena & - Ricarda M. Conceição & $02-08-1886$ & (B) & $\mathrm{J} / \mathrm{O}$ \\
\hline$(17)-$ Julia & - João A.Giovanni & $24-08-1886$ & (B) & $\mathrm{J} / \mathrm{O}$ \\
\hline (18) - José & - Manoel F.de Souza & $09-09-1886$ & (B) & $\mathrm{J} / \mathrm{O}$ \\
\hline (19) - Jeronimo & - Olympio da C. Braga & $09-09-1886$ & (B) & $\mathrm{J} / \mathrm{O}$ \\
\hline$(20)$ - Pio & - José F. dos Santos & $22-09-1886$ & (B) & $\mathrm{J} / \mathrm{O}$ \\
\hline (21) - Avelino & - João Monteiro & $06-10-1886$ & (B) & $\mathrm{J} / \mathrm{O}$ \\
\hline (22) - Manoel & - José Azevedo Paes & $08-10-1886$ & (B) & $\mathrm{J} / \mathrm{O}$ \\
\hline (23) - Caetana & - Manoel F. Chaves & $09-10-1886$ & (B) & $\mathrm{J} / \mathrm{O}$ \\
\hline (24) - Graciano & - Major Victoriano Feijó & $11-10-1886$ & (B) & $\mathrm{J} / \mathrm{O}$ \\
\hline (25) - Simão & - Manoel L. Costa & $15-10-1886$ & (B) & $\mathrm{J} / \mathrm{O}$ \\
\hline
\end{tabular}




\begin{tabular}{lllll}
\hline Nomes & Contratador & Data & Causa & Autoridade \\
\hline (26) - José & - Zeferino Rodrigues Fo & $18-10-1886$ & (B) & J/O \\
(27) - Sabino & - Maria Maia & $25-10-1886$ & (B) & J/O \\
(28) - Elias & - José Bitencourt & $28-10-1886$ & (B) & J/O \\
(29) - Julio & - Domingos Aguiar & $02-11-1886$ & (B) & $\mathrm{J} / \mathrm{O}$ \\
(30) - José Coelho & - José Coelho & $09-11-1886$ & (B) & $\mathrm{J} / \mathrm{O}$ \\
(31) - Alfredo & - Ten-Cel Joaquim Silva & $18-11-1886$ & (B) & $\mathrm{J} / \mathrm{O}$ \\
(32) - Oscar & - Idem & $19-11-1886$ & (B) & $\mathrm{J} / \mathrm{O}$ \\
(33) - Julia & - João A. Giovani & $24-11-1886$ & (B) & $\mathrm{J} / \mathrm{O}$ \\
(34) - Rufino & - João Gonçalves Lopes & $27-11-1886$ & (B) & $\mathrm{J} / \mathrm{O}$ \\
(35) - Vasco & - José Moreira & $04-12-1886$ & (B) & $\mathrm{J} / \mathrm{O}$ \\
(36) - Ventura & - José Silva & $16-12-1886$ & (B) & $\mathrm{J} / \mathrm{O}$ \\
(37) - José & - Ana Lopes & $20-12-1886$ & (B) & $\mathrm{J} / \mathrm{O}$ \\
(38) - Geraldo & - Joaquim Bastos & $20-12-1886$ & (B) & $\mathrm{J} / \mathrm{O}$ \\
(39) - Heleodoro & - Ana de Andrade & $20-12-1886$ & (B) & $\mathrm{J} / \mathrm{O}$ \\
(40) - João & - Gertrudes Carvalho & $23-12-1886$ & (B) & $\mathrm{J} / \mathrm{O}$ \\
(41) - Pedro & - Jesuino Souza & $24-12-1886$ & (A) & Sub/3 \\
\hline
\end{tabular}

FONTE: Códices de Policia n $103,104,105$, AHRGS.

Causas da prisáo: $(A)=$ desordem/embriaguez; $(B)=$ negou-se ao cumprimento do contrato de serviços.

Autoridaxdes: $\mathrm{N} / \mathrm{C}=$ nảo consta; $\mathrm{J} / \mathrm{O}=\mathrm{Juiz}$ de Orfăos; $\mathrm{DP}=$ Delegado de Polícia; Sub $/ 1^{\circ}=$ subdelegado do $1^{\circ}$ distrito; $\mathrm{CP}$ $=$ Chefe de Polícia; Sub $/ 3^{\circ}=$ subdelegado do $3^{\circ}$ distrito.

Abaixo citamos os de 1887:

\begin{tabular}{|c|c|c|c|c|}
\hline Nomes & Contratador & Data & Causa & Autoridades \\
\hline (1) - Gabriela & - Gen. Augusto C. da Silva & 04-janeiro & (B) & $\mathrm{J} / \mathrm{O}$ \\
\hline (2) - Francisco & - José Portela & 04-janeiro & (B) & $\mathrm{J} / \mathrm{O}$ \\
\hline (3) - Filomena & - Francisco Luiz de Mello & 18-janeiro & (B) & $\mathrm{J} / \mathrm{O}$ \\
\hline (4) - João Lourenço & - Cel. Domingos Leite & 19-janeiro & (B) & $\mathrm{J} / \mathrm{O}$ \\
\hline (5) - Simão & - Cel. Domingos Leite & 19-janeiro & (B) & $\mathrm{J} / \mathrm{O}$ \\
\hline (6) - Hilário & - não consta & 21-janeiro & (B) & $\mathrm{J} / \mathrm{O}$ \\
\hline (7) - Gabriela & - não consta & 08-fevereiro & (A) & $\mathrm{Sub} / 3^{\circ}$ \\
\hline (8) - Maria & - não consta & 12-fevereiro & (A) & $\mathrm{Sub} / 3^{\circ}$ \\
\hline (9) - Lúcio & - Joăo Gonçalves Lopes & 19-fevereiro & (B) & $\mathrm{J} / \mathrm{O}$ \\
\hline (10) - Antonio & - Idem & 19-fevereiro & (B) & $\mathrm{J} / \mathrm{O}$ \\
\hline (11) - Amélia & - não consta & 22-fevereiro & (A) & $\mathrm{D} / \mathrm{P}$ \\
\hline (12) - Maria Julia & - nāo consta & 22-fevereiro & (A) & $\mathrm{D} / \mathrm{P}$ \\
\hline (13) - Miguel Lopes & - João Lopes & 28-fevereiro & (B) & $\mathrm{J} / \mathrm{O}$ \\
\hline (14) - Luiz Retintim & - João Lopes & 03-março & (B) & $\mathrm{J} / \mathrm{O}$ \\
\hline (15) - Felipo André & - João Lopes & 03-março & (B) & $\mathrm{J} / \mathrm{O}$ \\
\hline$(16)$ - Lucas & - não consta & 08-março & (A) & $\mathrm{Sub} / 3^{\circ}$ \\
\hline (17) - Sophia & - não consta & 10 -março & (A) & $\mathrm{Sub} / 3^{\circ}$ \\
\hline (18) - Joana & - Joaquim Ant ${ }^{2}$ M. Santos & 12 -março & (B) & $\mathrm{J} / \mathrm{O}$ \\
\hline (19) - Ricardo & - Deolinda Cerqueira & 15 -março & (B) & $\mathrm{J} / \mathrm{O}$ \\
\hline (20) - Eufrásia & - Ventura Oliveira & 17 -março & (B) & $\mathrm{J} / \mathrm{O}$ \\
\hline
\end{tabular}




\begin{tabular}{lllll}
\hline Nomes & Contratador & Data & Causa & Autoridades \\
\hline (21) - Domingos & - João Lopes & 17-março & (B) & J/O \\
(22) - Lourenço & - João Celestino Salvatore & 22-março & (B) & J/O \\
(23) - Joana & - Carlos von Koseritz & 03-maio & (B) & J/O \\
(24) - Marcolino & - José F. Coelho & 16-junho & (B) & J/O \\
(25) - Gabriel & - Manoel de Figueiredo & 25-junho & (B) & J/O \\
(26) - José & - João da Silveira & 29-julho & (B) & J/O \\
(27) - Camila & - D. Deolinda F. da Silva & 01-agosto & (B) & J/O \\
(28) - Ana Machado - Cel. Ant Vitor M. Barreto 02-agosto & (B) & J/O \\
(29) - Marcolina & - Joăo PLitta Pinheiro & 18-agosto & (B) & J/O \\
(30) - Adão & - Manoel de Souza Pereira 04 -outubro & (B) & J/O
\end{tabular}

Salientamos que o número de negros presos é muito superior às listagens apontadas; mas para certificarmos de que eram realmente contratados, listamos apenas os que traziam explícita a sua condição.

Dos 41 contratados de 1886, 33 foram presos por se recusarem à prestação de serviços, quatro por desordem ou embriaguez e cinco não constava o motivo da prisão. Em 1887, dos 30 casos apontados, 24 foram presos por resistirem à prestação de serviços e seis por desordem ou embriaguez.

O jornal Mercantil, de 20 de agosto de 1887, publicou um artigo institulado "Os Emancipados", onde transcrevia uma carta do Chefe de Polícia ao Presidente da Província, datada de 17 de agosto. Nela, o jornal encontrava "acertadas providências para fazer cessar taes escândalos", promovidos pela "libertinagem entre indivíduos que foram tirados à vil condição de escravos". Apoiavam integralmente o teor da carta que dizia:

"Sem cogitar se as leis ofereciam ou não garantias suficientes para o cumprimento do ônus das condição de trabalho, pobres e ricos, os que tinham muitos cativos e os que apenas possuíam um cujo serviço diário constituia seu único recurso, todos na sua honesta confiança nas promessas feitas pelos promotores da idéia, abriram mão de sua propriedade sem hesitação. $\mathrm{O}$ movimento da capital foi o preludio da agitação geral da província, onde mediante a condição de prestação de serviço, ficaram livres cerca de 40 mil escravos. A transformação foi completa. A população riograndense cumpriu um dever, mas obrando com a precipitação do entusiasmo, não deu tempo ao governo para no desempenho de sua missão tutelar, cumprir igualmente o seu, estabelecendo como 
era necessário, certa ordem de medidas preventivas." (Jornal Mercantil, n² 170, ano XIV, 123 de agosto de 1887.)

Para o Chefe de Polícia, a "agitação" verificada e o "desprendimento" e "espontaneidade" dos senhores de escravos não permitiram que as autoridades se acautelassem com medidas necessárias, pois:

"[...] a sorte dos libertos, em virtude de antigos costumes e da educação que receberam, padecem sempre de uma aberração, senão perversão, do senso moral, a qual não the permite uma clara noção dos direitos e deveres, confundindo o bem com o mal, a liberdade com a licença."

E o resultado não se fez esperar:

"Com efeito, o que estamos presenciando nesta capital? Uma grande parte dos libertos de 1885 , violando a fé dos contratos e a todos surpreendendo pela sua ingratidão, abandonaram precipitadamente a casa de seus benfeitores tão depressa estiveram de posse da carta de alforria; outra não tardou a ser despedida como meio de se livrarem os senhores dos aborrecimentos das constantes infidelidades dos seus criados. Mais de duas partes dos contratados daquele tempo andam vagando pela cidade, maltrapilhos, sem abrigo e sem pão, frequentes hóspedes da cadeia e do hospital. Na campanha, a situação não é diferente; os libertos vivem em correrias, vagando durante o dia pelas estradas e tabernas e repartindo a noite entre o deboche e a rapina. Apesar da falta de braços não se encontra hoje um jornaleiro que se sujeite ao trabalho por algum tempo; devido aos hábitos de ociosidade que estão nele arraigados." (Idem acima.)

Segundo o Chefe de Polícia, tais hábitos só faziam crescer a prostituição, o "abuso da aguardente" e a desorganização do trabalho doméstico, de criação e de lavoura. Assim, era "preciso convencer 0 liberto que o direito da preguiça é imaginário, havendo só de real o dever do trabalho. É preciso, finalmente, que o poder público exerça sua ação moralizadora e educativa obrigando o liberto à dura lei do trabalho, fonte 
perene de felicidade e moralidade." (Jornal Mercantil, $\mathrm{n}^{\mathrm{Q}}$ 170, ano XIV, 13 de agosto de 1887.)

Em 30 de janeiro de 1888, o mesmo jornal, em artigo intitulado "Boa Medida", declara que:

"Os senhores Dr. Chefe de Polícia e Delegado acabam de pôr em prática uma medida que, forçosamente deve trazer excelentes resultados para a segurança individual da nossa capital. Depois do toque de recolher, todo o contratado que for encontrado nas ruas da cidade e, sem desígnio certo, será recolhido à cadeia. Essa medida estende-se também a certos e determinados indivíduos sem posição qualificada, que são encontrados depois daquela hora." (Jornal Mercantil, $\mathrm{n}^{2}$ 24, ano XV, 30 de janeiro de 1888.)

Como podemos notar, ainda no início de 1888 , havia interesses fortes na manutenção dos laços compulsórios mantidos com os contratados, assegurados com a continuidade da escravidão.

Percebemos com a leitura dos jornais e da correspondência policial um aumento da preocupação das autoridades em geral com o controle das classes trabalhadoras, num momento de crise generalizada do escravismo e, portanto, de seus instrumentos de controle. Usando a expressão de Ademir Gebara, era preciso "encontrar a alternativa ao chicote" (Gebara, 1986:59). Interessante talvez seja citar que, das 151 prisões efetuadas até abril de 1888 na cadeia civil de Porto Alegre, oito eram por ofensas à moral pública, 32 eram por "vagabundos" (22\%) e 71 por "desordem" (47\%); parece que a fuga ao trabalho formal e a resistência a certos padrōes de comportamento predominavam na capital no final da década de 80 (Jomal Mercantil, $\mathrm{n}^{2}$ 99, ano XV, 3 de maio de 1888).

O interesse na apresentação deste trabalho foi de chamar a atenção para a existência na província sulina de um grande número de trabalhadores ainda sujeitos aos laços compulsórios do escravismo, no final da década de 80.

A campanha emancipacionista de 1884 tinha como finalidade básica responder a pressão anti-escravista e, mantendo uma "escravidão disfarçada", garantir uma gradual transição. A libertação por contratos de serviço preenchia varias necessidades das elites regionais: conservava o 
controle sobre o trabalhador negro e sua força de trabalho; iludia as estatísticas e ainda livrava os "ex-senhores" dos impostos e taxas cobradas sobre os escravos:

"A emancipação - aparecendo o emancipado como livre - com prestação de serviços, procurava encobrir a realidade nelı presente, isto é, o estado servil não fora abolido e, assim, procuravam autoridades $\mathrm{e}$ políticos defender os interesses de que eram representantes. Entende-se, pois, que para protelar a abolição imediata o discurso político enfatizasse que era preciso preparar o escravo para a liberdade e que o preparo para a liberdade era prepará-lo para o trabalho como livre." (Piccolo, 1989:9.)

Os contratados não tardaram a perceber que foram enganados $\mathrm{e}$ passaram a resistir abertamente a permanência de seu estado servil.

Trata-se, assim, de considerar a transição ocorrida no Rio Grande do Sul como um processo longo e cheio de conflitos, onde a luta de classes determinou ajustes e reajustes constantes. Processo diretamente influenciado pela existência de fortes interesses na manutenção dos mecanismos de coerção característicos do sistema escravista, e que só foram ultrapassados mediante a ameaça de uma completa desorganização da produção provincial, resultado da rebeldia dos trabalhadores às diversas formas de escravidão disfarçada e de regulamentação do trabalho planejadas.

\section{Bibliografia}

GEBARA, Ademir, O Mercado de Trabalho Livre no Brasll. São Paulo, Brasiliense, 1986. PESAVENTO, Sandra J. Emergência dos subalternos - Trabalho Livre e Ordem Burguesa. Porto Alegre, UFRGS/FAPERGS, 1989.

PICCOLO, Helga L. O Discurso Abolicionista no Rio Grande do Sul. Porto Alegre, 1989. SAES, Décio. A Formação do Estado Burguês no Brasil (1888-1891). Rio de Janeiro, Paz e Terra, 1985. 